\title{
Introduction: Collaborative Production in the Creative Industries
}

\author{
James Graham and Alessandro Gandini ${ }^{\dagger}$ \\ ${ }^{*}$ Middlesex University \\ ${ }^{\dagger}$ King’s College, London
}

Collaboration has always functioned as the kernel of creative work. Yet from the artisanal workshops of the Renaissance masters to the globally networked start-ups of the twenty-first century, the character, context and consequences of creative collaboration have been mythologised and mystified in equal measure. Consider for example how, in the latter half of the twentieth century, high-profile success stories contributed to the building of an aura of around the magic that happens when popular artists collaborate. Think about Andy Warhol's collaborations with Jean-Michel Basquiat in the visual arts, or David Bowie's in music; about the way The Velvet Underground came together as a band through the addition of Reed to Cale, and then, at Warhol's suggestion, of Nico as singer. Or, more pertinently, think about how these collaborations catalysed a large-scale production process, through Warhol's Factory, that in conjunction with broader socio-economic transformations would play a part in reconfiguring creative production as an increasingly business-oriented process and influence trends in popular culture for decades to come (Berger, 2014).

\section{How to cite this book chapter:}

Graham, J. and Gandini, A. 2017. Introduction: Collaborative Production in the Creative Industries. In: Graham, J. and Gandini, A. (eds.). Collaborative Production in the Creative Industries. Pp. 1-14. London: University of Westminster Press. DOI: https://doi.org/10.16997/book4.a. License: CC-BY-NC-ND 4.0 
In contrast to the aura that pervades these iconic collaborations, consider for a moment those who dwell in the shadows cast by the limelight. How many unheralded individuals will also have played some kind of role in the work produced through the headline collaborations, nestling in the wings or noodling in studios? In the case of Bowie alone the list would include a bewildering array of producers and publicists, session musicians and sound engineers, fans and fashionistas. But even that list would overlook the socio-technical dimension of collaboration, for instance in how the qualities of Bowie's music also derive from the relationship between the spaces where collaboration occurs and the technologies and techniques through which it is afforded. Michel Callon (2005) describes such phenomena as the agencement of human and non-human agents, a concept that Antoine Hennion further develops in his discussion of 'the material organization of co-production' (Hennion and Farías 2015, 74) in the music studio. In his 1982 book Art Worlds, Howard Becker described the human actors involved in these processes as 'support personnel', with the named artist (or indeed artists) occupying the central node of 'a network of cooperating people, all of whose work is essential to the final outcome' (25). Although Becker's primary concern was the socio-aesthetic function of 'art worlds', the examples he uses range across the fields that comprise what are now known popularly and in cultural policy as the 'creative industries', from jazz musicians to film makers. In recent years research into creative labour and cultural work has tended to address the politics of production in these fields, but the socio-technical and aesthetic dimensions of collaborative creative work that Callon, Hennion and Becker draw to our attention have not been subject to the same kind of sustained enquiry.

This book aims to address this gap. Through case studies that range from TV showrunning to independent publishing, this collection develops a critical understanding of the integral role collaboration plays in contemporary forms of cultural production. It draws attention to the kinds of creative collaboration afforded through digital platforms and networked publics. It considers how these are incorporated into emergent market paradigms and investigates the complicated forms of subjectivity that develop as a consequence. But it also acknowledges historical continuities, not least in terms of the continued exploitation of Becker's 'support personnel', but also the resulting conflicts, resistance and alternative models that attend the precarious nature of contemporary cultural work. Finally, it attempts to situate developments in the cultural sphere in broader social context and economic contexts, where not just the ideal of artistic creativity, but more specifically the idea of artistic collaboration has come to assume central importance.

As Fredric Jameson (1984) once observed, the boundaries between high art and popular culture have become porous in late capitalism. The technological 
acceleration, cultural globalization and economic stagnation that hallmark late capitalism paved the way for a new model of capital accumulation and governance. In the neoliberal 'creative economy' that emerged from this conjuncture, culture would seem in all places and all ways to be commodified and subject to the logic of the market, and so comes to occupy a pivotal role in economic and political as well as social affairs (McGuigan, 2016). Conversely, the ideal type of the artist has evolved toward that of the 'creative', a hybrid socio-economic actor who carries the romantic ideal of the artist into the fragmented ecosystem of the market - where the individual is entrepreneurialised (Gandini, 2016) and the social relations around collaboration commodified, as Angela McRobbie (2015) amongst others has argued. The promise of creative autonomy that attaches to this figure functions in a similar way to what Sarah Brouillette (2016, np) describes as the 'ameliorate social balm' of culture and the arts for a generation born into a precarious world, where work is increasingly defined by competition, risk and individualization. This kind of work is doubtless fun and fulfilling for many, but the reality is that in the creative economy labour is casualised and its sociality divested of political purchase. It gives rise to a promotional culture that both fuels and normalises these transformations not least by occluding the intensification of the racial, gendered and international divisions of creative labour and cultural work (Curtin and Sanson, 2016). Nonetheless, the ethos and practices of artistic collaboration have flooded into the everyday practices and micro-politics of diverse industries across a global geography. Consequently this ethos, these practices and, perhaps most significantly, their much-hyped non-monetary payoffs, have become a feature of many different professions; yet they have also been thoroughly managerialised in the process. As Brouillette (2016) puts it:

The impetus against routine work has been brought into even the least apparently creative workplaces, in the form of a management commitment to crediting every employee's interest in self-realization and personal wellness. In certain industries, for instance the "cool" tech sector, attracting the best employees involves telling people that in their work they will experience the artist's unique "freedom."(np)

This scenario will be all too familiar to a great many young people today doing a job they 'love' yet struggling to make ends meet. So what is the appeal and nature of 'the artist's unique "freedom"' to the 'creative', exactly? In a listicle that appeared on the popular digital newsite Buzzfeed in 2014 (Rebolini) detailing 10 habits of creative people, 'collaborating' sits at number four - after 'moving', 'taking naps' and 'daydreaming. The listicle is designed to be consumed tongue-in-cheek. Bite-size self-improvement literature packaged as an ironic joke that will be shared instantly by acutely self-aware 'creative types' - the legions who spend so much of their lives in what Mark Banks (2014) calls 'the zone of cultural work', they are left (or rather, they are presumed to be left) with 
precious little time to engage more thoughtfully and critically with the culture they make as well as consume. Nonetheless, the appearance of collaboration on the list is substantiated by an anecdote starring one of the most renowned creative personalities of our times, the late Steve Jobs. It recounts the way in which Jobs redesigned the Pixar Studio campus in 1999 in order to better foster creative collaboration, based on the insight that 'human friction makes the sparks'(Lehrer, 2012).

For all the listicle's playfulness, the Jobs anecdote captures the auratic allure and affective pleasures of creative work that make it so appealing to young professionals - whilst simultaneously adding to the mysticism surrounding what it actually entails. Indeed, the listicle encapsulates the kind of reflexive irony that serves as the leitmotif of creative work in the era of neoliberalism more generally. The creative worker not only has to negotiate multiple dispositions simultaneously (autonomous artist and exploited labourer, and in many cases much more besides, parent, carer etc.), but to survive, let alone thrive, in this world they have to embrace, with stoic good humour, the doublethink necessary for living with the contradictions this entails. This paradoxical mode of subjectivity is addressed in this collection by a number of our contributors, who variously characterise it - from a state of 'ambivalence' strategically cultivated to negotiate socio-economic realities (Gandini, Bandinelli and Cossu), to a more abject condition of 'schizophrenia' (Wong) in thrall to the logic of late capitalism.

That such contradictions have emerged and come to define all manner of contemporary forms of work without great resistance ${ }^{1}$ is in no small part due to the way the ideas around collaboration derived from the arts have been appropriated by business schools and management gurus and subsequently filtered into practice and policy-making since the 1990s (Brouillette, 2014, O'Brien, 2014). Writing in the Harvard Business Review, for example, Ben Hecht (2013) argues that 'what we're seeing around the country is the coming together of non-traditional partners, and a willingness to embrace new ways of working together' (Hecht, 2013, np). Collaboration today is a multi-faceted beast, and collaborative production is undoubtedly an asset for many industries in information-based economies where, as Hecht argues, collaboration is seen as the new competition' (Hecht, 2013, np). Here, collaboration is figured as the primary driver of economic growth in a post-crisis world seemingly straight out of Jonathan Swift, that is, where governance has so successfully been captured by transnational corporations that the oligopolies they maintain at all costs can be construed as an exemplary model of creative collaboration at work on a global scale (Baird, 2016).

What happens, then, to an artistic notion of collaboration production in the fields from which the practice originated - Becker's (1982) art worlds - now that boundaries between 'art' and 'business' are blurred and these terms are no longer the oxymorons that sustained the traditional (if always already mythical) dichotomy? How has work in the creative industries been reshaped by the 
managerialised emphasis on collaboration that characterises the current landscape? In what ways might cultural production, conventionally understood, be transformed by the convergent dynamics of digital intermediation and consumption in the contemporary creative economy? This book originates from a symposium held at Middlesex University on November 2015 which gathered academics from media and cultural studies, sociology, literary and publishing studies, to address these questions and discuss the scope, nature and future of collaborative production in the creative industries.

In the contributions collected in this volume we highlight the two most prominent strands of discussion that emerged from this event. The first of these concerns the growing body of work which investigates the diverse forms and functions of media production. A number of recent studies have evidenced how, at the heart of production practices in the creative industries, lies the managerialised coordination of a number of people who come together in the expectation that their creative collaboration will amplify their self-worth, in all senses, as well as simply provide some form of financial remuneration. In a significant body of academic and also non-academic work, punctuated by the Production Studies reader (Mayer, Banks and Caldwell, 2009) and its recent Sequel! (Banks, Conor and Mayer, 2015), the work of media producers in creative and cultural industries has been extensively dissected and analysed. In parallel with empirical research into the consumption of media content exemplified in audience studies (Brooker, 2003), production studies research has brought to the surface complex sets of micro- and macro-production practices that characterise the professional work of creatives in industries such as television, film, radio and publishing. In both the Production Studies collections collaboration emerges as a definitive aspect of creative labour across a range of disciplines. To quote from the preface of Production Studies: The Sequel!:

Media production is an imbricated and prolonged process, one that can simultaneously be highly individualized and fully collaborative. Even labor that practitioners conduct while working alone is not produced in a vacuum: directors have producers, artists have grants from foundations or organizations, and journalists have a community of sources who now also tweet their own news-bytes (Banks, Conor and Mayer, 2015, pp. ix-x).

The second strand concerns the political economy of creative labour. An extensive body of research has looked at creative work in the media industries in relation to market devices and logics. This work has largely criticised the increasingly casualised and precarious nature of creative labour, unveiling notions of value, autonomy and self-realisation as serving the imperatives of neoliberalism (Curtin and Sanson, 2016). This kind of work is associated with a range of aesthetic pleasures and affective dispositions; yet these are invariably compromised through various forms and to varying degrees of co-option. As 
Hesmondhalgh and Baker (2010) put it, they offer the aspirant creative worker 'a complicated version of freedom'. Studies by, amongst others, Angela McRobbie ('Everyone is Creative', 2004, Be Creative, 2015), Andrew Ross (No-Collar, 2004, Nice Work If You Can Get It, 2009), David Hesmondhalgh and Sarah Baker (Creative Labour, 2011), as well as issue number 25 (7-8) of the journal Theory, Culture and Society (2008), hosting essays by Rosalind Gill and Andy Pratt, Susan Christopherson, Ned Rossiter amongst others, have paved the way in shifting this field into a broader perspective of inquiry. By framing creative work as one of the many forms of knowledge work that needs to be subject to critical analysis - i.e., without brandishing creativity as a lifestyle trend instrumental for capital accumulation and vice versa, as in the work of Richard Florida (2002) - these studies reveal how the attractions but also the problems with creative labour have become embedded in professions not traditionally thought of as being 'creative'.

Yet, the tendency within much of the literature that emerged out of these pivotal contributions has been to focus on the extent to which individual action in a networked context has become integral to the enactment of creative work, whilst implicitly taking for granted its highly competitive nature as a natural process in a context of flexible employment relations. Put differently, whilst casting light on the controversial evolution of work in the creative industries, this very same literature has simultaneously overlooked, to a large degree, the extent to which a networked individual has to engage in collaboration with others in order to be a recognised actor in such networked scenes, and how in this currency collaboration is one side of the coin - networking - where competition is the other side.A closer focus on collaborative practices therefore appears to be particularly timely in that it not only addresses an aporia within the literature on creative industries - concerning all the disciplines listed above but also focuses attention on the rise of 'collaboration' as the buzzword of the creative economy. It is notable that, whilst the creative economy was arguably flourishing as a research topic to a greater degree than its much-vaunted role as a catalyst for innovation and prosperity, the term 'collaboration' has gained an ever-increasing emphasis. Together with its often sibling buzzword 'sharing', the term 'collaboration' has become the fashionable shorthand for describing a socio-economic scenario that fosters individualised practices whilst at the same time demands 'compulsory' interaction with others in order to complete the individual projects that, ironically, cannot be achieved in isolation (Gandini, 2016). Here one encounters the rise of the terms 'collaborative consumption' (Botsman and Rogers, 2010) and 'sharing economy' (Slee, 2016) for describing the neoliberal logics of access for consumers of shared services - cab rides, home rentals, etc. - or the increasing relevance of a start-up culture founded on a shared belief in the complementarity of technological advancement and social innovation (Murray, Caulier-Grice and Mulgan, 2010) up to the coterminous rise of 'making', envisaged to be no less than a 'third industrial revolution' (Anderson, 2013). 
This collaborative turn in the creative economy is evidenced by the notable efforts of many funding bodies to finance and support research projects that investigate collaborative practices at various levels (O’Brien, 2015, McGuigan, 2016). The all encompassing role played by digital media, which in what Robin Millar (2016) calls a 'cybertarian' discourse is understood as the pre-eminent catalyst for new forms of production practices but also their depoliticisation, makes even more central the necessity to scrutinise how collaborative production takes place in contexts where personal branding melds with socialisation, cooperation with competition. Social media provide platforms that enable these new modes of collaborative production, which vary from typical market-based endeavours, such as apps or social networking sites, to processes which find their roots in the ethos of peer production (Bauwens, 2006; Benkler, 2006) and assume free access to common resources for the creation and distribution of content which escapes the logic of the market. Similarly, the nature of collaborative work is being transformed by the intermediation processes afforded by social media and platforms. For one example, in a context where new forms of untethered work, that may or may not rely on the access to a shared space in order for collaboration to occur, develop (Johns and Gratton, 2013), we witness the rise of Online Labour Markets where conventionally commercial modes of creative production - graphic design, copywriting, illustration, filmmaking, etc. - become algorithmically governed labour transactions with concerning implications (Gandini, Pais and Beraldo, 2016). In response to this fragmented scenario, and with the aim of mapping the more media-based collaborative practices that live within it, this collection plots a course through the multi-disciplinary aspects of collaboration across a range of creative industries. The chapters that follow challenge some of the key assumptions that characterise the understanding of the sector as a whole, and its framing in the contemporary socio-economic context.

The opening chapter, co-authored by Alessandro Gandini, Carolina Bandinelli and Alberto Cossu, presents a framing discussion of the fractured subjectivity that characterises the three main social actors who have been long typically portrayed, from various perspectives, as the main protagonists in the collaborative turn in the creative industries: freelancers, social entrepreneurs and artists. The authors draw from different empirical research projects to offer a comparative discussion of these subjects, their practices and ways of making a living, investigating the common aspects that characterise their subjectivity. The authors argue that the working stance of these subjects entails a mix of collaboration and competition, solidarity and market logic, including a somewhat frustrated potential to coalesce as a collective subject as a result of their inability of the same subjects to recognise themselves as one.

The example of freelancers, social entrepreneurs and artists discussed in this chapter illustrates a general phenomenon that this collection as a whole begins 
to map. In the new geography that is charted here, the role of collaboration within the diverse forms of cultural work that characterises the creative industries emerges as a key driver through which the economic is being reembedded in the social - a process initiated after the economic crisis, in many sectors of the economy, as value is reformulated (Arvidsson and Peitersen, 2013). This process is ongoing and challenges established notions of production and consumption, work and play, profit and social impact, with the aim of reconciling the often dichotomous views these terms convey.

This theoretical framing is further expanded in chapter two, where Jacob Matthews investigates the political economy of collaboration in a paper largely inspired by the notion of 'digital labour' (Fuchs, 2014), offering a critique of what he terms 'collaborative economy discourse'. With the emergence of the socalled 'web 2.0', the 'collaborative economy', Matthews argues, has been object of a discourse at the centre of which lies the role of platforms operating across diverse fields of cultural and creative production. By discussing the concept of 'digital intermediation' by platform and its 'collaborative' nature, this chapter unpacks a few of the most relevant theoretical propositions with regards to cultural capitalisation and production as usually mobilised within the political economy of culture industries, and questions the extent to which this brings changes in the relations of production within them.

In the chapters that follow immediately after, authors address in more detail the constituency of what Adam Arvidsson (2013) calls 'collaborative publics'. In chapter three, Rosamund considers the impact on publishing of the 'productive consumer publics' (Arvidsson, 2010) afforded by the Wattpad platform. Davies begins by situating Wattpad in the context of emergent peer-to-peer (P2P) collaborative production before discussing its specific features: how it provides a launch pad for fledgling writers, an audience development opportunity for established writers, and a marketing service for brands. Wattpad offers its users a community but also a marketplace, and as such articulates with the transformations in traditional publishing, as well as with the wider field of platform-enabled commerce described by Matthews. Having considered these aspects, Davies argues that Wattpad's predominantly young female fan community represents a 'productive consumer public' that might exercise significant social and political as well as economic influence, and that the platform as such provides a potentially game-changing model for collaborative production in publishing.

The publishing angle developed by Davies brings the reader to chapter four, where James Graham considers the spectre of auteurship in neoliberal cultural economies. Graham uses the example of Ponte City, the 2015 Deutsche Börse Photography Prize prize-winning photobook by Mikhael Subotzky and Patrick Waterhouse, to examine the role of collaborative production in book publishing in a 'post-digital age' - a term deployed by Alessandro Ludovico (2013) to account for contexts in which print is being revitalised rather than replaced. Graham argues that Ponte City provides an example of how the independent 
publishing sector resists certain aspects of digital transformation in the wider creative industries, but also of how it struggles to escape complicity with the governing neoliberal imperative for such transformations. By fully crediting all those with creative input, the book provides a platform from which its contributors are able to recoup their collective creative investments in the form of symbolic capital. Similar to the workings of the film industry that this in some ways comes to resemble, however, these returns are not evenly distributed. This niche sector of the publishing industry projects collaborative production as the kind of 'art world' Howard Becker (1982) described. Yet this model of networked collaborative production remains largely in thrall to a neoliberal cultural economy dominated by promotional authorship, evidenced in this discussion by the auteur roles played by the book's editor and publisher.

Following Graham's discussion of independent publishing, Leora Hadas's chapter examines how collaborative production in the US TV industry is organised, and to a large extent overshadowed, by the promotional authorship of the showrunner. Focusing on the work of Bad Robot, the production company of 'quality TV' doyen J. J. Abrams, the chapter traces a range of collaborative practices in the context of authorship as a promotional device and of the auteur as brand. While the creation of a television show is a complex collaborative endeavour, Abram's promotional authorship obscures the logic of production in the process of legitimation. Drawing on comparisons with the historical workshop model of the Italian Renaissance, in which corporate creative work would be validated and branded by the signature of the master, Hadas argues that the Abrams-Bad Robot model as a significant development in a media landscape in which the demand for authorship exceeds possible supply. In this scenario the showrunner's 'position of absolute author ... takes on the cast of property manager'.

Chapter six, authored by Jamie Clarke, develops this enquiry into the evolving function of the auteur-figure in the context of collaborative production through a discussion of the 2015 Oscar nominees for best cinematography. Clarke begins by discussing how digital workflows have displaced the collaborative axis of director-cinematographer as author of the final look of the film. As control has shifted towards postproduction, the craft boundaries previously policed by union jurisdiction are blurred and the autonomy of the cinematographer challenged. In close readings of Mr. Turner (directed by Mike Leigh, cinematography by Dick Pope), The Grand Budapest Hotel (directed by Wes Anderson, cinematography by Robert Yeoman) and Ida (directed by Paweł Pawlikowski, cinematography by Lukasz Zal and Ryszard Penczewski), Clarke identifies a common trope of 'digital naturalism' and argues that it serves a strategic function. The elegiac portrayal of superannuated artistic craft in Mr. Turner is taken to encapsulate the contemporary situation of the cinematographer. Just as the artful use of 'digital naturalism' serves to commemorate Turner's genius, it also promotes and protects that of the cinematographer. The dominance of 'digital naturalism' at the 2015 Oscars therefore testifies to the 
resistance of a community of cinematographers to their usurpation by digital post-production - by reasserting the primacy of a neo-traditional workflow, but in the process also reinforcing the concomitant divisions of labour.

This trilogy of chapters paves the way for contributions that delve into more specific case studies where collaboration and collaborative productions are observed 'at work' across the digital domain. Chapter seven, authored by Dinu Gabriel Munteanu, discusses the microblogging and social networking site Tumblr, showing how the 'curatorial' collaborative authorship practice within a community of Tumblr users evidences an autonomous cultural practice that rows against the currents of the neoliberal cultural economy described by other contributors. Notwithstanding the anomalous position of Tumblr in the current social network ecosphere - it originally adopted a 'freemium' commercial model whereby it neither served advertising nor sold its users' data. Munteanu shows how the circulatory dynamics of the platform challenge conventional understandings of originality, authorship and commodification. The content shared and curated among the community of 'young nostalgics' destabilises the three conventional sites of an image (production, image, audience), and in so doing enables individual agency and autonomy through the practice of creative collaboration.

In chapter eight, Karen Patel offers a reflection on the way artists engage in reciprocal forms of digital-based interaction and collaboration across social media for purposes of mutual recognition in the scene. Patel argues that this is illustrative of a logic that may be described through Pierre Bourdieu's concept of illusio, as associations and consensus are crucial for performing expertise via public endorsement from other people and institutions on social media, which thus contribute to artists' performance of expertise. Patel demonstrates that on social media, artists negotiate their expertise construction by engaging in a dialectical relationship between competition and collaboration, which contributes to their overall performance of expertise.

This is followed by chapter nine where Miranda Campbell offers a feminist perspective on collaborative production and analyses Girls Rock Camp in Canada as a 'community of practice' (Lave and Wenger 1991; Wenger 1998, 2010). Using participant observation and examining the camp's pedagogies and cultural norms, the chapter evaluates the notion of a community of practice in a context of music collaboration and learning. Campbell argued in favour of the instrumental role of collaboration in widening access to the usually maledominated music scenes, while at the same time warning that collaborative modes of production alone cannot intervene against systemic barriers to entry to creative work or lack of equity in the creative industries at large.

In the final chapter, creative professional and arts activist Ashley Wong discusses the collaborative turn of the creative economy as evidence of the schizophrenic condition of capitalism in the digital age. The chapter provides an autoethnographic account of the struggle to reconcile the demands of a day job in a digital start-up with longstanding investment in independent creative projects 
and arts activism. By reflexively exploring the conditions of surviving in a postcrisis neoliberal economy where creative workers are forced to take on multiple roles and professional identities at the same time, Wong warns us of the inner conflicts as well as the social struggles such an economy carries with it, which often go largely overlooked by those within this same scene.

If we are effectively witnessing a structural transformation in the cultures of work and in the morphology of the workforce in the contemporary cultural economy (see Rifkin 2014, 1996; Moretti 2012), then the key insights offered by this collection are that the role of collaboration in creative and cultural work is key to this transformation, but that the experience and outcomes of such work are contradictory to say the least. Some contributions highlight how platforms and paradigms have emerged in recent years which aim to facilitate creative collaboration, spreading value across individuals and organisations. Yet in these and other contributions there is also evidence that this value is not equally distributed. The buzz around collaborative production also serves to mask exploitation, as cultural and creative workers have little choice but to embrace individualisation and self-exploitation in undertaking work that increasingly revolves around the production of author-brands that function as the primary currency of the cultural economy. This being the case collaborative production in the creative industries looks set to continue to prove as contradictory as it is enabling, enmeshed as it is in politics and policies, practices and publics

\section{Notes}

1 This is not to discount the significance and success of resistance from within the creative sector as such - witness internationalist arts activism, the social art movement, or the resistance to corporate control central to the films analysed by Jamie Clarke. Rather, the observation is that in almost all cases the effects of such resistance, whilst real, have tended be been contained within their respective fields, while the transformations in general employment and in the more specific subjectivities and dispositions attending so-called 'creative work' described here have developed relatively unchecked.

\section{References}

Anderson, C. (2013). Makers: The New Industrial Revolution. New York: Crown Books. 
Arvidsson, A. and Peitersen, N. (2013). The Ethical Economy: Rebuilding Value After the Crisis. New York: Columbia University Press.

Arvidsson, A., Malossi, G. and Naro, S. (2010). Passionate work? Labour conditions in the Milan fashion industry. Journal for Cultural Research, 14(3): 295-309.

Baird, V. (2016). Smiley-faced monopolists. New Internationalist, July/August: $12-16$.

Banks, M. (2014). 'Being in the Zone' of cultural work, Culture Unbound, 6: 241-62.

Banks, M., Conor, B. and Mayer, V. (2015). Production Studies: The Sequel! Cultural Studies of Global Media Industries. New York: Routledge.

Bauwens, M. (2006). The political economy of peer production. Post-autistic Economics Review, 37(28): 33-44.

Becker, H. (1982). Art Worlds. Berkeley, CA: University of California Press.

Benkler, Y. (2006). The Wealth of Networks. Princeton, NJ: Princeton University Press.

Berger, D. (2014). Projected Art History: Biopics, Celebrity Culture, and the Popularizing of American Art. Trans. Brigitte Pichon and Dorian Rudnytsky. London: Bloomsbury.

Botsman, R., and Rogers, R. (2010). What's Mine is Yours: The Rise of Collaborative Consumption. New York: HarperCollins.

Bourdieu, P., \& Johnson, R. (1993). The Field of Cultural Production: Essays on Art and Literature. New York: Columbia University Press.

Brooker, W. (2003). The Audience Studies Reader. New York: Routledge.

Brouillette, S. (2014). Literature and the Creative Economy. Standford, CA: Stanford University Press.

Brouillette, S. (2016, June). On the Creative Economy: An Apostate Thesis. Retrieved from http://www.humag.co/features/on-the-creative-economy.

Callon, M. (2005). Why virtualism paves the way to political impotence: A reply to Daniel Miller's critique of The Laws of the Markets. Economic Sociology, 6(2): 3-20.

Curtin, M., \& Sanson, K. (2016). Precarious Creativity: Global Media, Local Labor. Oakland, CA: University of California Press.

Florida, R. (2002) The Rise of the Creative Class. New York: Basic Books.

Fuchs, C. (2014) Digital Labour and Karl Marx, London, Routledge.

Gandini, A. (2016). The Reputation Economy: Understanding Knowledge Work in Digital Society. Basingstoke: Palgrave Macmillan.

Gandini, A., Pais, I., \& Beraldo, D. (2016). Reputation and trust on online labour markets: The reputation economy of elance. Work Organisation, Labour and Globalisation, 10(1), 27-43.

Hecht, B. (2013). Why collaboration is the new competition. Harvard Business Review. Retrieved from https://hbr.org/2013/01/collaboration-is-the-newcompe. 
Hennion, A and Farías, I. (2015). For a sociology of maquettes: An interview with Antoine Hennion. In Farías, I. and Wilkie, A. (Eds.) Studio Studies: Operations, Topologies \& Displacements. Abingdon and New York: Routledge.

Hesmondhalgh, D. and Baker, S. (2010) A very complicated version of freedom: Conditions and experiences of creative labour in three cultural industries. Variant, 41. Retrieved from http://www.variant.org.uk/pdfs/issue41/ complicated41.pdf.

Hesmondhalgh, D. and Baker, S. (2011). Creative Labour: Media Work in Three Cultural Industries. Abingdon: Routledge.

Jameson, F. (1984). Postmodernism, or, the cultural logic of late capitalism. New Left Review, 146 (July-August): 59-92.

Johns, T. and Gratton, L. (2013). The third wave of virtual work. Harvard Business Review, 91.1: 66-73.

Lave, J., \& Wenger, E. (1991). Situated Learning: Legitimate Peripheral Participation, Cambridge: Cambridge University Press.

Lehrer, J. (2012). Imagine: How Creativity Works. Boston, MA: Houghton Miffin Harcourt.

Ludovico, A. (2013). Post-Digital Print: The Mutation of Publishing since 1894. Santa Monica, CA: Ram Publications

Mayer, V., Banks, M., and Caldwell, J. (2009). Production Studies: Cultural Studies of Media Industries. London: Routledge.

McGuigan, J. (2016). Neoliberal Culture. Basingstoke: Palgrave Macmillan.

McRobbie, A. (2002). Clubs to companies: Notes on the decline of political culture on speeded-up creative worlds. Cultural Studies 16(4): 516-31.

- (2002). Everyone is creative: Artists as pioneers of the new economy. In E. Silva, T. Bennett, Contemporary Culture and Everyday Life, Durham: Sociology Press, 186-99.

- (2015). Be Creative. Making a Living in the New Culture Industries. London: Wiley.

Millar, R. (2016). Cybertarian flexibility - when prosumers joint the cognitariat, all that is scholarship melts into air. In M. Curtin \& K. Sanson (2016), Precarious Creativity: Global Media, Local Labor (p. 336). Oakland, CA: University of California Press, pp. 19-32.

Moretti, E. (2012) The New Geography of Jobs. Boston, MA: Houghton Mifflin Harcourt.

Murray, R., Caulier-Grice, J., \& Mulgan, G. (2010). The Open Book of Social Innovation. London: National Endowment for Science, Technology and the Art.

O'Brien, D. (2014) Cultural Policy: Management, Value and Modernity in the Creative Industries. Abingdon-on-Thames: Routledge.

Platman, K. (2004). 'Portfolio careers' and the search for flexibility in later life. Work, Employment \& Society, 18(3): 573-599. 
Rebolini, A. (2014). 10 habits of highly creative people. Buzzfeed. Retrieved from https://www.buzzfeed.com/ariannarebolini/habits-of-highly-creativepeople?utm_term=.si8xWg2w3\#.bn0LXZR7o

Rifkin, J. (2014). The Zero Marginal Cost Society: The Internet of Things, The Collaborative Commons, and the Eclipse of Capitalism. London: Macmillan.

- (1995). The End of Work: The Decline of the Global Labor Force and the Dawn of the Post-Market Era. New York: Putnam Publishing Group.

Ross, A. (2004). No-Collar: The Humane Workplace and Its Hidden Costs. New York: Basic Books.

- (2009). Nice Work If You Can Get It. Life and Labor in Precarious Times. New York: New York University Press, 2009.

Slee, T. (2016). What's Yours is Mine: Against the Sharing Economy. New York: OR Books.

Theory, Culture and Society. Vol. 25 (7-8), December 2008. Retrieved from http://tcs.sagepub.com/content/25/7-8.toc.

Wenger, E. (1998). Communities of Practice: Learning, Meaning and Identity. Cambridge: Cambridge University Press.

. (2010). Communities of Practice and Social Learning Systems: The career of a concept. In C. Blackmore (Ed.) Social Learning Systems and Communities of Practice. London: Springer Verlag, pp. 179-98. 